\title{
Formação em Matemática de Licenciandos em Pedagogia: uma análise à luz do pluralismo metodológico
}

\section{Pedagogy Licentiate Mathematics Education: an analysis in the light of the methodologic pluralism}

\author{
Jaqueline de Morais Costa* \\ Lúcia Virginia Mamcasz Viginheski ${ }^{* *}$ \\ Edson Jacinski ${ }^{* * *}$ \\ Nilcéia Aparecida Maciel Pinheiro ${ }^{* * * *}$
}

\begin{abstract}
Resumo
A pesquisa tem como objetivo a análise das operações realizadas pelos futuros professores, após formação para o ensino de Matemática. Apresenta uma abordagem qualitativa, sendo utilizado o estudo interpretativo como estratégia metodológica. $\mathrm{O}$ estudo foi desenvolvido em uma turma do Curso de Pedagogia de uma instituição particular de Ensino Superior, no interior do Estado do Paraná, Brasil. O referencial teórico adotado traz contribuições de estudos realizados sobre as formas de elaboração do conteúdo em questão, assim como as contribuições das ideias de Feyerabend (1977) acerca do emprego do pluralismo metodológico. Os resultados apontaram a prevalência de um perfil racionalista, uma vez que foram mínimas as mudanças percebidas no posicionamento epistemológico dos acadêmicos pesquisados, após concluída a etapa de formação.
\end{abstract}

Palavras-chave: Ensino de Matemática. Pluralismo Metodológico. Números e Operações. Curso de Pedagogia.

\begin{abstract}
The research has as main objective the analysis of the operations made by future teachers, after the degree course for Mathematics teaching. It presents a qualitative approach, using the interpretive study as a methodological strategy. The study was developed in a Pedagogy Course class of a Private Higher Education Institution, in a city in the countryside of the state of Parana, Brazil. The theoretical reference brings contributions from studies made

\footnotetext{
* Doutora em Ensino de Ciência e Tecnologia pela Universidade Tecnológica Federal do Paraná (UTFPR), Ponta Grossa/PR. Professora Colaboradora na Universidade Estadual de Ponta Grossa (UEPG), Ponta Grossa/PR. Docente na Faculdade Sagrada Família (FASF), Ponta Grossa/PR. Endereço para correspondência: Rua Rio Ribeira, $\mathrm{n}^{\circ}$ 161, Bairro Neves, Ponta Grossa/PR, CEP: 84020-460. E-mail: j.moraiscosta @ hotmail.com.

${ }^{* *}$ Doutora em Ensino de Ciência e Tecnologia pela Universidade Tecnológica Federal do Paraná (UTFPR), Ponta Grossa/PR. Docente pela Faculdade Guairacá, Guarapuava/PR. Endereço para correspondência: Rua Maria Marcondes Ribas, $\mathrm{n}^{\circ}$ 73, Bairro Santana, Guarapuava/PR, CEP: 85070-696. E-mail: lmamcaszviginheski@gmail.com.

*** Doutor em Educação Científica e Tecnológica pela Universidade Federal de Santa Catarina (UFSC). Professor do Ensino Básico, Técnico e Tecnológico pela Universidade Tecnológica Federal do Paraná (UTFPR), Ponta Grossa/PR. Endereço para correspondência: Av Monteiro Lobato s/n - Km 04 - Departamento de Ensino Universidade Tecnológica Federal do Paraná - CEP 84016-210 - Ponta Grossa/PR. E-mail: ejacinski@utfpr.edu.br.

**** Doutora em Educação Científica e Tecnológica pela Universidade Federal de Santa Catarina (UFSC). Professora Titular pela Universidade Tecnológica Federal do Paraná (UTFPR), Ponta Grossa/PR. Endereço para correspondência: Av Monteiro Lobato, s/n - Km 04, Ponta Grossa/PR, CEP 84016-210. E-mail: nilceia@utfpr.edu.br.
} 
about those contents elaboration, as well as the contributions of Feyerabend's ideas on the methodological pluralism usage. The results pointed out the domination of a rationalist profile, since it was possible to observe minimal changes in the epistemological posture of the surveyed students, after concluding the educational stage.

Keywords: Mathematics Teaching. Methodological. Pluralism. Numbers and Operations. Pedagogy Course.

\section{Introdução}

Tem se tornado cada vez mais comum o discurso que questiona o que seria realmente necessário se ensinar na escola. Lamentavelmente, muitos estudantes e professores indagam se certos conteúdos são mesmo importantes, tendo como principal argumento o fato de que pouco ou nada empregarão desses conhecimentos no cotidiano, sendo, muitas vezes, a Matemática o principal alvo dessas indagações.

Ao selecionar os conteúdos que envolverão a construção de um currículo, é necessário refletir sobre quais deles teriam sua presença justificada, considerando sua origem, valor e contexto. Santos (2008) traz, como consideração importante, que o conhecimento precisa ser utilizado como ferramenta de compreensão do meio social no qual o sujeito está inserido, levando em conta aspectos culturais e de comunicação.

Entende-se que essa construção se inicia nos primeiros anos de escolarização, sendo que os documentos norteadores da organização curricular, o Referencial Curricular Nacional para a Educação Infantil - RCNEI (BRASIL, 1998b) e os Parâmetros Curriculares Nacionais para o Ensino Fundamental - PCNs (BRASIL, 1998a), primam pelo desenvolvimento cognitivo, estruturação do pensamento e desenvolvimento do raciocínio lógico-matemático para resolução de problemas presentes no meio social no qual a criança se encontra, para que esta possa intervir intencionalmente e de maneira autônoma em seu entorno.

Para que essas premissas se concretizem, a prática docente deve ser orientada de forma a levar os estudantes a elaborarem conceitos matemáticos que se constituem como base para a continuidade de seus estudos e também construam ferramentas intelectuais, as quais permitam a eles interpretar situações de sua realidade. Portanto, fazem-se necessários investimentos em metodologias que propiciem uma educação voltada à formação que atenda as necessidades sociais atuais.

Apesar dessa discussão não se tratar de um assunto recente, a escola brasileira ainda não conseguiu superar suas fragilidades. Exemplo disso é o relatório do Programa Internacional de Avaliação dos Estudantes - PISA, divulgado em 2012, pela Organização para Cooperação e Desenvolvimento Econômico - OECD (2012), o qual informou que 67,1\% dos alunos apresentaram baixo desempenho em Matemática, o que significa que, na melhor 
das hipóteses, eles podem extrair informações relevantes a partir de uma única fonte e podem usar algoritmos básicos, fórmulas, procedimentos ou convenções para resolver problemas envolvendo números inteiros; apenas $1,1 \%$ dos estudantes obteve um melhor desempenho em Matemática, o que significa que eles podem desenvolver e trabalhar com modelos para situações complexas, estrategicamente, usando as habilidades de pensamento e raciocínio amplo e bem desenvolvido (OECD, 2012). Cabe ressaltar que essa avaliação é prestada por estudantes com 15 anos de idade, ou seja, que concluíram o Ensino Fundamental e estão ingressando no Ensino Médio.

Diante desse cenário, cabe refletir sobre as críticas a respeito da formação escolar, publicadas por Nogueira (2001), Pais (2001; 2006), Maranhão e Igliori (2003), Pavanello (2004) e Santos (2008), os quais, sobre diferentes argumentos, relatam que a escola não está cumprindo com o seu papel, a partir do momento em que privilegia somente a formação de conhecimentos conceituais. Além disso, índices de avaliação demonstram que estudantes não conseguem responder da forma esperada as questões de avaliação matemática, salientando a necessidade de buscar uma forma de ensino mais efetivo.

Um dos fatores que pode contribuir para a realidade apresentada refere-se à formação inicial do professor. Segundo os PCNs (BRASIL, 1998a), professores com lacunas na formação podem desenvolver uma prática de ensino insatisfatória. A partir do exposto, motivados pela preocupação a respeito do conhecimento que o professor tem sobre os conteúdos os quais serão ensinados aos estudantes e a função destes na formação de cidadãos, os pesquisadores foram levados a investigar, por meio da pesquisa aplicada, uma turma de acadêmicos do curso de Pedagogia, de uma faculdade particular, no município de Guarapuava, Paraná, Brasil.

Buscou-se identificar, entre os sujeitos da pesquisa, como esses futuros professores dos Anos Iniciais da escolarização (Infantil e Fundamental) elaboraram conceitos relacionados ao conteúdo números e operações no decorrer de sua escolaridade. A pesquisa apresenta como problema para a investigação: Como acadêmicos do curso de Pedagogia respondem a questões referentes às operações básicas, depois de concluída a etapa de formação para o ensino de Matemática?

Sendo assim, o objetivo da investigação consiste em analisar como os acadêmicos, após a formação para o ensino de Matemática, expressam a resolução das operações básicas.

Para alcançar o objetivo proposto, a pesquisa apresenta como arcabouço teórico estudos sobre as formas de elaboração do conteúdo operações fundamentais no decorrer da história e seus respectivos contextos, assim como o ensino deste conteúdo nas escolas. Busca- 
se também apresentar as contribuições das ideias postuladas por Feyerabend (1977), nas quais se buscou traçar um comparativo entre suas publicações sobre o método científico e a interpretação acerca do emprego do pluralismo metodológico.

\section{Marco teórico}

\subsection{Reflexões sobre a Matemática: do contexto histórico ao ensino em sala de aula}

Sabe-se que uma das funções da escola é transmitir conhecimentos que foram elaborados pela humanidade no decorrer da história. Entre eles, o presente estudo enfocará os conhecimentos matemáticos, desenvolvidos por diferentes civilizações que viveram em épocas remotas e distintas e que, apesar de não terem conhecimento umas das outras, desenvolveram formas similares de entender e explicar fatos e fenômenos, organizando as explicações em sistemas, em busca pela sobrevivência e da transcendência (D’AMBRÓSIO, 2011). Esses conhecimentos foram sistematizados e transmitidos entre as gerações por meio da educação formal escolar.

Segundo as Diretrizes Curriculares da Educação Básica - Matemática - DCE (PARANÁ, 2008), a civilização grega foi uma das primeiras a inserir os conhecimentos matemáticos na formação dos filhos dos aristocratas, a partir de um ensino com base no racionalismo.

Para Hessen (2000, p. 36), o racionalismo é "o ponto de vista epistemológico que enxerga no pensamento, na razão, a principal fonte do conhecimento humano”. Prossegue o autor afirmando que, para o racionalismo, o conhecimento é validado pela sua necessidade lógica e pelo reconhecimento universal.

Hessen (2000) aponta o conhecimento matemático como um exemplo da expressão do racionalismo, ao apresentar aspectos dedutivos e conceituais predominantes no decorrer de seu desenvolvimento. $\mathrm{O}$ autor exemplifica essa concepção racionalista com a geometria, cujos conceitos derivam de conceitos superiores e axiomas, independentes da experiência, obedecendo a suas próprias leis.

As ideias racionais influenciaram por muito tempo o ensino de Matemática, de forma abstrata, com verdades inquestionáveis, justificando a existência da ordem universal e imutável da sociedade e da natureza (PARANÁ, 2008).

Entretanto, muitas mudanças relacionadas ao ensino aconteceram a partir das transformações sociais, políticas e econômicas. Em épocas contemporâneas, frente à 
necessidade de novas mudanças, currículos foram elaborados propondo o ensino da disciplina de forma a relacionar os conceitos cotidianos aos conceitos científicos, promover a aprendizagem e o desenvolvimento do estudante, buscando superar o ensino centrado em "procedimentos mecânicos, desprovidos de significados para os alunos" (BRASIL, 1998a, p. $15)$.

Orientando esse discurso para a área de Matemática, foco de estudo desta pesquisa, um dos temas elencados para a composição dos currículos escolares são números e operações. Assim como outros, ele foi elaborado a partir das interações entre o homem, a natureza e a sociedade ao longo da história da humanidade, considerado de fundamental importância para a resolução de diferentes problemas no cotidiano das pessoas. Para os PCN (BRASIL, 1998a), o conhecimento desse conteúdo, além de ser um instrumento eficaz para resolução de determinados problemas, é também objeto de estudo em si mesmo, considerando as propriedades, as inter-relações e o modo como foi historicamente construído.

Entre as primeiras atividades desenvolvidas pelo ser humano relacionado ao conhecimento dos números e às operações, destaca-se a contagem, desenvolvida primitivamente em função da necessidade do controle quantitativo de objetos, rebanhos, população, entre outros.

Ifrah (1994) apresenta de forma interessante alguns marcos da história da Matemática. A contagem abstrata e o desenvolvimento de sistemas de numeração a partir do princípio de base impulsionou o desenvolvimento do conhecimento matemático. Povos primitivos desenvolveram sistemas de numeração a partir de diferentes bases, como os babilônios, os egípcios, os gregos, os maias, os romanos, entre outros. Além disso, alguns povos desenvolveram contadores mecânicos, com o objetivo de operar com as quantidades. Entre eles, pode-se relacionar o milenar suan pan, de origem chinesa, o soroban japonês, que foi desenvolvido a partir da introdução do suan pan no Japão, o stchoty, contador desenvolvido pelos russos, entre outros.

Ainda segundo o autor, os diferentes sistemas de numeração possivelmente influenciaram no desenvolvimento do sistema de numeração decimal pelo povo hindu, aproximadamente no século $\mathrm{V}$, estabelecendo-se também nesta mesma época as bases do cálculo escrito utilizado e ensinado pelas escolas atualmente.

Já os árabes foram os principais disseminadores no ocidente do conhecimento matemático desenvolvido pelos hindus. Na Europa, entretanto, houve resistência para a adoção dos novos conhecimentos trazidos por eles.

Apesar dos entraves, os novos métodos de cálculo foram sendo incorporados na 
cultura europeia, ao mesmo tempo em que os ábacos continuavam sendo utilizados para a conferência dos cálculos realizados por algoritmos escritos (IFRAH, 1994).

Se para a humanidade os conhecimentos relacionados aos números e operações foram elaborados a partir de suas necessidades, na escola, o ensino desse conteúdo, conforme discutido pelos PCN (BRASIL 1998a), também deveria ser ensinado de modo a satisfazer as necessidades do ser humano. Além disso, conforme explanado anteriormente, diferentes civilizações, em épocas também diferentes, desenvolveram formas de raciocínio matemático, bem como instrumentos para apoio a este raciocínio. Contudo, o cenário presente na Educação se reduz a métodos unívocos, desprezando, com isso, a diversidade, bem como o contexto. Isso leva à reflexão sobre a necessidade de se repensar na Formação Inicial dos futuros professores, de forma a despertar para um ensino de Matemática atrelado a sua história e ao seu contexto.

\subsection{Contribuições de Feyerabend: pluralismo metodológico}

Na busca pela construção de um ensino que contrapõe a domesticação, tão criticada por Freire (2002), como base epistemológica para o presente estudo foram tomadas as contribuições de Feyerabend.

Paul Karl Feyerabend é de origem austríaca e viveu entre os anos de 1924 e 1994. Foi cientista, doutor em Física e filósofo da área das Humanidades, da qual recebeu o título de doutor honoris causa em Letras e Humanidades da Universidade de Chicago (REGNER, 1996). Pode-se destacar que este autor foi fortemente criticado pelos renomados epistemólogos, como Popper, Lakatos e Kuhn, devido às suas ideias pouco ortodoxas, publicadas principalmente em sua obra mais conhecida, Contra o Método (FEYERABEND, 1977).

Sua posição, conforme explica Siqueira-Batista, Siqueira-Batista e Schramm (2005, p. 244), contrapõe o racionalismo, "trazendo novos tons para a questão do conhecimento científico, os quais compõem uma elegante paisagem, defendendo a adoção de uma 'metodologia pluralista', a partir de uma estratégia reconhecida como anarquista". Dessa forma, compreende-se que anarquismo epistemológico é uma postura crítica que confronta o racionalismo e o monismo metodológico.

A crítica feita por Feyerabend ao racionalismo, explicada por Regner (1996), foi à eficácia de procedimentos baseados em razões, que de forma impositiva, legitimam o proceder e o colocam como verdade, uma vez que considera que o conhecimento não é 
definitivo. O conhecimento, sem dúvidas, sofre interferências da história, do contexto e do sujeito na leitura de um fenômeno ou objeto de estudo.

Feyerabend (1977) esclarece diferenças no termo anarquismo, quando este se situa nas esferas política, religiosa ou epistemológica. As duas primeiras se posicionam contrários à ordem política ou religiosa, colocando na espontaneidade humana a opção de escolha. Quanto à epistemologia, o autor explica:

\begin{abstract}
O caminho que leva a tal objetivo é claro. Uma ciência que insiste em ser a detentora do único método correto e dos únicos resultados aceitáveis é ideologia e deve ser separada do Estado e, especialmente, dos processos de educação. Cabe ensiná-la, mas tão-somente àqueles que decidiram aderir a essa particular superstição. De outra parte, uma ciência que renuncie a essas pretensões totalitárias deixa de ser independente e autônoma e poderia ser ensinada sob diferentes combinações (mito e cosmologia moderna seria uma dessas combinações). Está claro que todo empreendimento tem o direito de exigir que os a ele devotados se preparem de maneira especial e pode, inclusive, impor a aceitação de certa ideologia (FEYERABEND, 1977, p. 464).
\end{abstract}

Assim, entende-se que no debate epistemológico contemporâneo, o anarquismo não pode ser compreendido como ausência do método, mas sim uma postura contrária ao reconhecimento de "um conjunto único, fixo, restrito de regras que se pretenda universalmente válido, para toda e qualquer situação - ou seja, contra algo que se pretenda erigir como o método, como a característica distintiva, demarcadora do que seja ciência", conforme salienta Regner (1996, p. 234). A autora faz ainda a leitura de que o anarquismo epistemológico, defendido por Feyerabend, pode ser traduzido como "pluralismo metodológico". O mesmo discurso pode ser encontrado em Laburu, Arruda e Nardi (2003).

Tal asserção pode ser verificada na afirmação de Feyerabend (1977, p. 71): “O pluralismo das teorias e das doutrinas metafísicas não é apenas importante para a metodologia; também é parte essencial da concepção humanitária”.

Com base nas concepções de Feyerabend, colocando-se como defensores do modelo pluralista, Laburu, Arruda e Nardi (2003) perfilham a adoção do pluralismo metodológico na área do ensino. Os autores justificam que essa postura busca romper com a visão simplista do homem do processo ensino-aprendizagem, pois reconhece as necessidades humanas, sociais e o contexto presente. Além disso, por alusão à história da humanidade, os autores entendem que os modelos educacionais são provisórios mediante às circunstâncias do cenário social. Por fim, salientam a reflexão que é possível realizar, à luz do pluralismo metodológico, sobre o ato de ensinar e, por consequência, torna-se um tema interessante a ser tratado, quando o assunto é formação de professores.

O pluralismo metodológico não combate nenhum procedimento metodológico, mas é contrário à ideia de adoção de um único e assumi-lo em suas regras como forma unívoca de 
ensino. Seu objetivo é "argumentar no sentido de que todos os modelos e metodologias, inclusive as mais óbvias, têm vantagens e restrições" (LABURU; ARRUDA; NARDI, 2003, p. 251).

Tal posicionamento está baseado na preocupação sobre formação do professor, tendo como pano de fundo uma única forma compreendida como verdadeira para o ensino. As consequências deste posicionamento pode ser a limitação da reflexão crítica do futuro docente e de sua compreensão holística sobre o processo ensino-aprendizagem.

\begin{abstract}
Um professor inserido numa proposta deste tipo é interessante que seja um inconformado, em última instância. Deve ultrapassar a concepção de uma verdade pedagógica autoritária como fórmula universal, solução do ensino e da aprendizagem do ser humano, para se elevar à ideia de uma verdade como procura. Pois, quando se torna seguidor monástico de uma teoria pedagógica, condutora de uma ou poucas ações didáticas, em desconsideração de outras, geralmente é culpado por não duvidar da mesma ou dessas últimas. Detentor da verdade, quando toma a teoria por si, propõe apenas impô-la aos outros pelas técnicas mais eficazes dela derivadas, criando com isso um obscurantismo pedagógico que procura asilo e refúgio na tecnicidade (LABURU; ARRUDA; NARDI, 2003, p. 254).
\end{abstract}

Considerando a natureza aplicada e interdisciplinar da Educação e a sua complexidade, seria muito ingênuo conceber que uma única postura metodológica seria suficiente para atender a todas as necessidades de formação dos alunos. A preocupação é o conhecimento superficial de uma dada postura metodológica por parte do professor, que, por imposição ou "modismo", pode acabar adotando-a sem a devida reflexão das fragilidades que esta pode apresentar em sua prática pedagógica. Reflexos dessas práticas podem ter sua "parcela de culpa" nos problemas educacionais enfrentados atualmente, entre os quais salientamos a área de Matemática.

\title{
3 Procedimentos metodológicos
}

O trabalho apresenta, quanto à natureza dos dados, uma abordagem qualitativa, tratando-se de um estudo interpretativo, com base em Moreira e Caleffe (2008).

A pesquisa foi levada a efeito em uma turma com 20 (vinte) acadêmicos do curso de Pedagogia de uma faculdade particular do município de Guarapuava, Paraná, Brasil, cujas idades variavam entre dezenove (19) e trinta e sete (37) anos, sendo $45 \%$ dos pesquisados em idade acadêmica normal, ou seja, concluíram seus estudos na Educação Básica há menos de dez anos.

A disciplina Fundamentos e Metodologia para o ensino de Matemática compõe a matriz curricular do referido curso e tem como objetivo proporcionar, aos acadêmicos de 
Pedagogia, fundamentação teórica e prática para o ensino de Matemática na Educação Infantil e nos Anos Iniciais do Ensino Fundamental.

Entre os conteúdos abordados na disciplina, são propostos estudos teóricos e práticos sobre os conteúdos ensinados na Educação Básica, como no caso desta pesquisa, o conteúdo Números e Operações.

No início do semestre, foi aplicada uma avaliação com o objetivo de verificar os conhecimentos que os acadêmicos tinham sobre os conteúdos que futuramente iriam ensinar. As questões relacionadas ao conteúdo Números e Operações foram reaplicadas ao final do semestre, com o objetivo de verificar mudanças conceituais após o desenvolvimento do trabalho no decorrer do semestre.

O trabalho com o conteúdo Números e Operações teve duração de aproximadamente vinte horas-aula. Foram abordadas temáticas como construção do conceito de número, sistema de numeração decimal, operações fundamentais, como adição, subtração, multiplicação e divisão. Entre as atividades relacionadas ao conteúdo, foram desenvolvidas práticas de laboratório, exploração de materiais didáticos, estruturados ou não, utilizados no ensino do conteúdo como objetos para contagem, réguas numéricas, dominó, baralho, soroban e jogos diversos. As atividades se deram a partir de orientações propostas pelos PCN (BRASIL, 1998a), Fernandes et al. (2006), Nunes e Bryant (1997), Carraher; Carraher e Schliemann (1995), Kamii e Declark (1991), entre outros.

Os dados foram coletados a partir das produções dos acadêmicos e interpretados pela análise qualitativa do conteúdo.

\section{Resultados e discussões}

No início do semestre foi aplicada uma avaliação com o objetivo de investigar os conhecimentos dos acadêmicos a respeito dos conteúdos matemáticos que irão ensinar na Educação Infantil ou nos Anos Iniciais do Ensino Fundamental. Entre as questões, foi solicitado aos acadêmicos que resolvessem algumas operações com números inteiros, decimais e fracionários, justificando os procedimentos adotados na resolução do algoritmo. Cabe ressaltar que não foi determinado que elas devessem ser resolvidas a partir do algoritmo padrão. As operações solicitadas foram as seguintes:
I. $1547+879$
II. $721-538$
III. $678,43 \times 6,5$ 
IV. $13945: 37$

V. $1 / 3+3 / 4$

VI. $7 / 8: 4 / 5$

Foram obtidos os seguintes resultados, os quais foram sintetizados na Tabela 1:

Tabela1 - Síntese dos resultados da avaliação inicial

\begin{tabular}{lllllll}
\hline Operação & $\begin{array}{l}\text { Algoritmo } \\
\text { padrão sem } \\
\text { justificativa }\end{array}$ & $\begin{array}{l}\text { Outro } \\
\text { algoritmo }\end{array}$ & $\begin{array}{l}\text { Algoritmo } \\
\text { padrão com } \\
\text { justificativa }\end{array}$ & $\begin{array}{l}\text { Somente } \\
\text { resultado }\end{array}$ & $\begin{array}{l}\text { Não } \\
\text { resolvido }\end{array}$ & $\begin{array}{l}\text { Total } \\
\text { de } \\
\text { acertos }\end{array}$ \\
\hline I & 10 & 0 & 07 & 02 & 01 & 18 \\
II & 12 & 0 & 05 & 02 & 01 & 14 \\
III & 10 & 0 & 06 & 01 & 03 & 4 \\
IV & 08 & 01 & 04 & 02 & 05 & 10 \\
V & 0 & 03 & 0 & 15 & 02 & 0 \\
VI & 0 & 0 & 0 & 13 & 07 & 03 \\
\hline
\end{tabular}

Foi possível perceber pelos resultados que a maioria dos acadêmicos resolveu as operações fundamentais a partir do algoritmo padrão. Parece que os professores fazem uso apenas desse recurso de cálculo, ensinando aos estudantes a técnica pela técnica, da mesma forma como aprenderam, sem fazer uso de outros encaminhamentos metodológicos e de outros recursos que realmente propiciem a aprendizagem do cálculo.

$\mathrm{O}$ único acadêmico que não fez uso do algoritmo padrão para resolver a operação IV fez da seguinte forma:

\begin{tabular}{|c|c|c|c|c|c|c|}
\hline$x 1$ & 37 & & 37 & & 185 & 333 \\
\hline$x 2$ & 74 & + & 37 & + & 37 & 37 \\
\hline$x 3$ & 111 & & 74 & & 222 & 370 \\
\hline$x 4$ & 148 & + & 37 & + & 37 & \\
\hline$x 5$ & 185 & & 111 & & 259 & \\
\hline$x 6$ & 222 & + & 37 & + & 37 & \\
\hline$x 7$ & 259 & & 148 & & 296 & \\
\hline$x 8$ & 296 & + & 37 & + & 37 & \\
\hline$x 9$ & 333 & & 185 & & 333 & \\
\hline$x 10$ & 370 & & & & & \\
\hline
\end{tabular}

Após concluir a operação, explicou da seguinte forma seu procedimento:

Conta de divisão que teve como meio a tabuada do número 37, com seu resultado de 378, essa conta teve como etapas a divisão do número 13945, que teve três etapas de divisão com sobra de 29 (Acadêmico 7, Arquivo dos autores, 2014).

Observa-se a tentativa da resolução por meio da utilização da adição de parcelas iguais a 37 como uma estratégia para efetuar a divisão, consideradas pelo acadêmico como etapas. 
Apesar de o acadêmico citar em sua explicação o resultado encontrado, a operação não chegou a ser finalizada. Provavelmente esta seja mais uma técnica ensinada pelos professores nas escolas para resolver a operação.

Para Kamii e Declark (1991, p. 93), “aprender a somar, subtrair e multiplicar, no entanto, envolve um raciocínio lógico matemático, e raciocínio não é técnica. O raciocínio não se desenvolve e nem pode ser aperfeiçoado meramente através da prática”.

Na mesma linha de pensamento, Viana (2010) aponta que muitos estudantes concluem a Educação Básica sem apresentarem domínio nas operações básicas, tanto com relação às regras e procedimentos, quanto com relação à compreensão. Prossegue o autor, considerando que a realização do algoritmo padrão, de forma mecânica, tem sua utilidade quando se quer apenas o resultado, porém, quando se depara com o ato de ensinar, precisa-se explicar aquilo que se faz mecanicamente.

A avaliação quantitativa, no caso, os erros e acertos das operações não são relevantes nesse estudo, porém, ao observar o total de acertos das operações, percebe-se que, a partir da análise das justificativas de alguns acadêmicos, é passível de dúvida a compreensão do processo empregado por parte deles, ou seja, é possível que utilizem corretamente as etapas de cálculo do algoritmo, mesmo sem consciência do porquê daquele procedimento. Essa questão é observada em algumas justificativas, conforme palavras ou expressões destacadas pelos pesquisadores:

Uma operação de adição com milhar e centenas inicia-se da esquerda para a direita sempre da unidade, em seguida dezena, centena e milhar (Acadêmico 1, Arquivo dos autores, 2014).

Porque a professora ensinou que, quando se tem um número menor que outro, para tirar, se empresta do outro (Acadêmico 2, Arquivo dos autores, 2014).

Nessa operação também começamos da direita para a esquerda, pois na subtração precisamos emprestar da casa do vizinho (Acadêmico 3, Arquivo dos autores, 2014).

Na multiplicação com vírgula não lembro direito como resolve e que lugar certo coloca a vírgula depois de resolvido (Acadêmico 4, Arquivo dos autores, 2014).

Não aprendi como se faz conta de dividir com 2 ou mais números na chave (Acadêmico 5, Arquivo dos autores, 2014).

Constatou-se na avaliação inicial que, para muitos acadêmicos, os conceitos envolvidos ainda não estavam consolidados, conforme observado em suas justificativas. Dessa forma, no início das atividades, algumas questões sobre as operações fundamentais, propostas por Viana (2010), foram apresentadas aos acadêmicos, com o objetivo de proporcionar uma reflexão acerca das operações fundamentais. Entre elas: por que utilizamos 
o algoritmo da divisão que se apresenta na horizontal, enquanto nos outros se apresenta na vertical; por que na adição, subtração e na multiplicação inicia-se a operação das ordens menores para as maiores, ou seja, das unidades para dezenas e centenas, enquanto que na divisão se inicia da ordem maior para a menor; quais as propriedades que os algoritmos revelam e ocultam; como seria a operação utilizando outros algoritmos.

A partir desses e outros questionamentos, foi realizado um trabalho prático sobre a construção do conceito do número e das operações fundamentais. Para isso, foram desenvolvidas atividades propostas por Fernandes et al. (2006) e Kamii e Declark (1991), de forma a ressignificar o ensino da Matemática, ou seja, propor um ensino de Matemática contextualizado, dinâmico, que leve os estudantes a elaborarem os conceitos matemáticos, superando a prática tradicional de ensino.

Dentro da perspectiva do pluralismo metodológico, Laburu, Arruda e Nardi (2003, p. 256) contribuem para esse estudo, o qual é possível ilustrar com a seguinte afirmação:

\begin{abstract}
Ademais, é fundamental, quando dessa formação, que se anseie por uma postura de não doutrinamento, no sentido de tornar corriqueiro o questionamento daquilo que parece natural, fazendo com que se explorem outras possibilidades para inovação didática, quando se percebem necessidades não satisfeitas, no que diz respeito aos compromissos pedagógicos. Para isso, é necessário que se crie, durante a formação docente, uma atitude de espírito em permanente disposição para melhorar a prática instrucional, evitando a rotina, rompendo com a inércia de um ensino monótono e desalentador, procurando o professor estar sempre em dúvida com relação às soluções propostas para os problemas da educação escolar.
\end{abstract}

$\mathrm{Na}$ busca por diferentes possibilidades de ensino, com vistas a melhorias e diversificação de procedimentos metodológicos, propuseram-se aos acadêmicos diferentes atividades.

Para desenvolver o trabalho sobre o pensamento lógico, foi utilizado o material Blocos Lógicos, constituído por blocos, os quais são estruturados pelos atributos cor, forma, tamanho e espessura. Com esse material, foram exploradas as noções de seriação, classificação, estruturação do pensamento lógico, inclusão, exclusão, entre outros, conhecimentos estes que contribuem para a elaboração do conceito de número e, consequentemente, das operações (SIMONS, 2007).

As autoras Kamii e Declark (1991), fundamentadas teoricamente em Piaget, consideram que a criança constrói o conhecimento lógico matemático a partir das relações criadas entre ela e os objetos; daí a importância da utilização de materiais concretos e atividades lúdicas. Para as autoras, a criança constrói o conceito de número a partir da abstração reflexiva pela sua própria ação mental de relacionar objetos; portanto, esse conceito não pode ser ensinado, uma vez que ele é construído internamente pela criança, a partir da 
capacidade natural de pensar e a adição também não precisa ser ensinada, uma vez que a construção do número implica a repetição da adição de " 1 ".

As Réguas Numéricas, outro material didático comum nas escolas, constituído por réguas cujos tamanhos variam entre uma e dez unidades, foram utilizadas como um material de apoio para facilitar a compreensão da continuidade no trabalho com números. Com elas, os conceitos de adição, subtração, composição de números e o cálculo mental tornam-se significativos para a criança (FERNANDES et al., 2006).

Kamii e Declark (1991, p. 190) e Fernandes et al. (2006) enumeram também vários jogos que podem ser desenvolvidos com a utilização de baralhos, para a construção do conceito de número, como Batalha, Pescaria, Memória, Setes, Rouba monte. Esses jogos também foram abordados no decorrer das atividades.

Os jogos de agrupamento e troca foram utilizados com o objetivo de conceituar número, estruturar sistemas de numeração, entre eles o decimal, e realizar operações a partir de situações concretas, com diferentes tipos de materiais, estruturados ou não. Entre os materiais não estruturados foram utilizados palitos de fósforo, caixinhas, pacotinhos, canudinhos de refrigerante, palitos de picolé; entre os estruturados, foram utilizados os triângulos, para trabalhar com agrupamentos de quatro em quatro (base 4) e o Material Dourado, para agrupamentos de dez em dez (base 10).

Fernandes et al. (2006) relacionam uma série de jogos que favorecem a compreensão e o entendimento do sistema de numeral decimal, os quais também foram desenvolvidos na pesquisa. Entre eles, o Jogo livre, Quem é quem, Brincadeira do banco, Jogo do nunca, Jogo do nunca quatro solto, Jogo do nunca dez solto. Segundo os autores (ibid., p. 66), esses jogos proporcionam "a concretização da lógica do sistema do conceito do sistema de numeração decimal, valor posicional, base 10, culminando com o estudo das 4 operações fundamentais".

Além do aporte construtivista, durante a formação dos acadêmicos, foi explorado o ensino baseado na História da Matemática. A base do ensino considerou diferentes algoritmos escritos, exemplificados por Viana (2010), assim como foram explorados outros algoritmos, desenvolvidos pelos povos como os babilônios, egípcios e outros (EVES, 2004).

Como material de apoio, o soroban, contador mecânico japonês, foi inserido nas atividades, com o objetivo de ampliar os recursos utilizados para o cálculo, além do cálculo escrito a partir do algoritmo padrão.

Segundo o Manual de Técnicas Operatórias (BRASIL, 2009), esse instrumento é utilizado no Brasil, principalmente por estudantes cegos e traz contribuições na área do raciocínio lógico, estimulando o desenvolvimento de habilidades mentais. 
O documento apresenta as três principais técnicas de operação difundidas no país, quais sejam, a técnica oriental adaptada para pessoas com deficiência visual, cujas operações são realizadas das ordens maiores para as menores; a técnica ocidental, cujas operações são realizadas das ordens menores para as maiores e a técnica do complementar 5 e 10, difundida no Brasil pelos primeiros imigrantes japoneses.

$\mathrm{Na}$ pesquisa foram desenvolvidas atividades que contemplavam as duas primeiras técnicas, principalmente com o objetivo de promover reflexões acerca das questões propostas por Viana (2010) sobre as operações, anteriormente abordadas. Ao realizarem as operações no soroban, foi possível perceber que muitos acadêmicos conseguiram responder questões as quais não foram respondidas a partir do algoritmo padrão.

As atividades desenvolvidas contemplaram não somente operações com números naturais, mas também números racionais, como os decimais e os fracionários.

Ao final do semestre, as operações I, II, III, IV, V e VI, propostas na avaliação inicial, foram reaplicadas e o resultado expresso na Tabela 2 :

Tabela 2 - Síntese dos resultados da avaliação final

\begin{tabular}{lllllll}
\hline Operação & $\begin{array}{l}\text { Algoritmo } \\
\text { padrão sem } \\
\text { justificativa }\end{array}$ & $\begin{array}{l}\text { Outro } \\
\text { algoritmo }\end{array}$ & $\begin{array}{l}\text { Algoritmo } \\
\text { padrão com } \\
\text { justificativa }\end{array}$ & $\begin{array}{l}\text { Somente } \\
\text { resultado }\end{array}$ & $\begin{array}{l}\text { Não } \\
\text { resolvido }\end{array}$ & $\begin{array}{l}\text { Total } \\
\text { de } \\
\text { acertos }\end{array}$ \\
\hline I & 07 & 0 & 10 & 02 & 01 & 18 \\
II & 09 & 0 & 07 & 02 & 02 & 14 \\
III & 11 & 0 & 05 & 02 & 02 & 08 \\
IV & 08 & 01 & 04 & 02 & 05 & 10 \\
V & 1 & 0 & 0 & 17 & 02 & 01 \\
VI & 0 & 0 & 0 & 15 & 05 & 05 \\
\hline
\end{tabular}

Fonte: Autores, (2014)

Estabelecendo um comparativo com a Tabela 1, percebem-se algumas mudanças nos resultados, porém é possível considerar que não ocorreram modificações com relação à adoção de diferentes algoritmos para o cálculo. Da mesma forma que na primeira avaliação, apenas um acadêmico fez uso de um algoritmo diferente do padrão para a divisão.

Tais informações mostram que os acadêmicos pesquisados tiveram em toda sua vida escolar uma forma unívoca de resolução de algoritmos. O tempo limitado de trabalho diversificado aplicado, durante a disciplina Fundamentos e Metodologia para o Ensino de Matemática, demonstrou-se insuficiente para desenvolver no aluno a capacidade de adoção de formas diferenciadas de desenvolver o cálculo. Laburu, Arruda e Nardi (2003) já alertaram sobre a preocupação da formação do professor, quando este tem como pano de fundo uma única forma compreendida como verdadeira para o ensino. A consequência desse posicionamento pode ser a limitação da reflexão crítica do futuro docente e de sua compreensão holística sobre o processo ensino-aprendizagem. 
Aqui é possível também perceber o quanto a visão racionalista está impregnada na formação dos acadêmicos, pois mesmo após as intervenções, ainda foi possível perceber fortes traços da metodologia tradicional aprendida na Escola Básica. Em Hessen (2000, p. 37), é possível interpretar esses dados, pois o autor explana que o racionalismo tem um estreito relacionamento com a Matemática:

É óbvio que um determinado tipo de conhecimento serviu de modelo à interpretação racionalista do conhecimento. E não é difícil dizer qual seja: é o conhecimento matemático [...]. É da matemática, mostra-nos a história, que vêm quase todos os representantes do racionalismo.

Porém, é importante salientar que, apesar da adoção de diferentes estratégias de resolução das operações por meio de diferentes algoritmos serem tímidas, foi possível encontrar mudanças conceituais. Estas podem ser verificadas nas seguintes justificativas, em que se destacam os termos empregados:

Transformamos as unidades em dezenas antes de fazer a subtração (Acadêmico 6, Arquivo dos autores, 2014).

Utilizei a transformação do número para resolver essa atividade (Acadêmico 7, sobre a subtração, Arquivo dos autores, 2014).

As expressões dos acadêmicos, referindo-se a transformações, são indicativas de apropriação dos conceitos relacionados aos números e suas operações. Era comum, no decorrer da pesquisa, os acadêmicos fazerem uso de expressões como empresta do vizinho, vai um, locuções estas resultantes do cálculo mecânico, a partir de regras. O termo transformação indica a compreensão do sistema, cuja base é decimal e assume valor posicional.

Outras justificativas foram destacadas nas análises:

Iniciei ela pelo lado direito, mas não que não se possa ser iniciado pelo esquerdo, não existe lado correto para começar (Acadêmico 8, sobre a adição. Arquivo dos autores, 2014).

Fiz dessa maneira, pois aprendi assim, mas agora, sei que podemos fazer começando pelo lado esquerdo também, o resultado será o mesmo (Acadêmico 3, sobre adição. Arquivo dos autores, 2014).

Devemos colocar unidade com unidade, dezena com dezena, centena com centena, resolver não necessariamente da esquerda para a direita (Acadêmico 1, sobre a adição. Arquivo dos autores, 2014).

Apesar de a maioria dos acadêmicos haverem resolvido as operações pelo algoritmo padrão, tanto na avaliação inicial, como na avaliação final, foi possível perceber que eles começaram a despertar para a tratativa dos conteúdos de forma diferenciada. Um exemplo é comparando os textos dos acadêmicos, citados anteriormente, após o desenvolvimento das 
aulas, e o questionamento de uma acadêmica durante as aulas fazendo uso do soroban: "Mas professora, é errado começar da esquerda para a direita. Tem que ser da direita para a esquerda" (Acadêmica 13, Arquivo dos autores, 2014). A adoção de um único método não só orienta para a resolução de atividades de forma engessada, mas a própria postura do professor, formado nesta perspectiva, desconsidera a aprendizagem de forma globalizada.

Buscando se desvencilhar dessa postura racionalizada é que ocorre a postura do pluralismo metodológico, a qual é ilustrada pelos autores Laburu, Arruda e Nardi (2003, p. 254) da seguinte forma:

O mestre pluralista não possui a verdade e não admite que alguém possa possuí-la, pois a mesma é para cada um o sentido da sua própria situação. Não se recusa a examinar, a inovar, a arriscar e a experimentar qualquer proposta, pois o seu primeiro compromisso racional deveria estar orientado a favor da qualidade da aprendizagem e do saber dos seus alunos, não podendo os mesmos ser imaginados desconciliados e deixando de preservar atitudes libertadoras, de vida completa e gratificante.

Ao verificar todo o processo de encaminhamento da disciplina, os progressos e as estagnações, percebe-se o quão é importante que se reflita, discuta-se e se avalie as posturas metodológicas adotadas em todas as etapas da educação, percebendo-se as consequências das opções que a escola faz.

As autoras Lerner e Sadovsky (1996) trazem contribuições às discussões aqui apresentadas. Para elas, é comum na prática de ensino os professores: fornecerem a seus estudantes respostas ao que não foi por eles questionado; respostas encontradas por eles serem ignoradas e; desapreço à necessidade de novos questionamentos. Essas autoras consideram que uma opção didática seria atentar o conhecimento prévio dos estudantes, seus questionamentos, seus problemas e conflitos a serem superados.

Para atender a tais apontamentos, Lerner e Sadovsky (1996) propõem um ensino do conteúdo Números e Operações a partir de uma organização didática que permita aos estudantes as ações de operar - ordenar - produzir - interpretar, agrupando essas ações em duas categorias, a ordem e as operações matemáticas. Na primeira categoria, o professor pode alvitrar aos estudantes atividades, contextualizando-as com as vivências cotidianas deles com os números, fazendo uso de comparações. Na sequência, a utilização da ordem seria como um recurso para produzir ou interpretar resultados, bem como encontrar regularidades nas escritas numéricas com vista à compreensão do sistema de numeração decimal e a adequação da notação convencional.

Relativo às operações matemáticas, as autoras consideram que os estudantes, ao enfrentar situações problemas, buscam estratégias e procedimentos próprios para resolvê-los, 
os quais estão vinculados à organização do sistema de numeração decimal. Para isso, é importante que o professor proponha a resolução das operações confrontando procedimentos, oportunizando aos estudantes que registrem a maneira como resolveram a operação, o que permite a consciência do procedimento e a possibilidade de comparação de seus resultados com os resultados dos outros. Para Lerner e Sadovsky (1996, p. 151):

O que importa, então, não é que uma atividade está categorizada como "tradicional"
ou "inovadora", o que importa é que as propostas de trabalho reúnam determinadas
condições: partir dos problemas formulados pelo uso da numeração escrita,
contemplar diferentes procedimentos, admitir diferentes respostas, gerar alguma
aprendizagem a respeito do sistema de numeração em todos os membros do grupo,
favorecer o debate e a circulação da informação, garantir a interação com a
numeração escrita convencional, propiciar uma crescente autonomia na busca da
informação, aproximar - na medida do possível - o uso escolar ao uso social da
notação numérica.

É possível entender, a partir do que é proposto por Lerner e Sadovsky (1996), que as operações entre números podem ser realizados por outros caminhos, diferentes aos dos algoritmos convencionais, e que os professores, ao assumirem uma prática de ensino, necessita considerar essa premissa, pois assim contribuirão para que avanços aconteçam na compreensão e apropriação desse conteúdo matemático.

Apesar de ainda não ter sido possível identificar um significativo avanço no uso de diferentes estratégias para resolução das questões propostas, quantitativamente, foi possível realizar uma análise no que se refere aos acertos das operações. É possível observar, nos dados apresentados na Tabela II, um maior número de acertos em comparação com a avaliação inicial, o que pode se configurar como aprendizado ocorrido na resolução das operações durante o desenvolvimento das aulas.

\section{Considerações finais}

Por meio da presente pesquisa foi possível verificar o quanto a postura epistemológica de cunho racionalista está fortemente enraizada na formação dos estudantes. Tal verificação foi percebida pela análise das respostas presentes nos pré-testes aplicados e sua continuidade nos pós-testes, em relação à resolução do cálculo, com persistência no uso quase unívoco do algoritmo padrão.

A preocupação com tal situação nasce no estudo sobre a história da Matemática e quantas construções, culturas e formas de se conceber o conteúdo matemático são desconsiderados ao se privilegiar apenas uma forma de realização de cálculos como correta. Isso reforça o quão racionalista a escola se tornou, mesmo com discurso diferente, conforme 
os próprios Parâmetros Curriculares Nacionais (BRASIL, 1998a) e as Diretrizes Curriculares do Estado do Paraná (PARANÁ, 2008) orientam.

Pode-se perceber que o pluralismo metodológico, dentro da postura epistemológica defendida por Feyerabend e aplicadas à Educação por Laburu, Arruda e Naardi (2003), busca superar esse posicionamento epistemológico, trazendo a importância do reconhecimento dos méritos de cada concepção metodológica de ensino, bem como de suas fragilidades.

Mesmo procurando desenvolver uma formação dentro desta perspectiva, sentiu-se a dificuldade em deixar certos preceitos construídos e calcificados, pois foi uma vida escolar inteira pregando uma "verdade". Dessa forma, identificou-se a necessidade de realização de um trabalho educativo que permita a diversidade desde o início da formação escolar. Contudo, para que esta aconteça, é imprescindível rever a formação do professor, não apenas em algumas disciplinas isoladas, mas na concretização do currículo nos aspectos mais globais.

No trabalho realizado, foi possível identificar um avanço em certos aspectos, como conhecimento de que existem outras formas de desenvolver o cálculo e a aprendizagem da realização dos mesmos. Porém, reconhece-se que haverá necessidade de intensificar os esforços na continuidade da formação destes alunos, para que além de reconhecer as diferentes formas, possam também aplicá-las, para que então, futuramente, tornem-se professores que favoreçam a seus alunos a apropriação do conhecimento historicamente produzido pela humanidade e não apenas meros repetidores de técnicas mecânicas, vazias de significados.

\section{Referências}

BRASIL. Parâmetros curriculares nacionais: matemática. Brasília: MEC/SEF, 1998a.

. Referencial curricular nacional para a educação infantil. Brasília: MEC/SEF, 1998b.

Soroban: manual de técnicas operatórias para pessoas com deficiência visual. Brasília: MEC/SEESP, 2009.

CARRAHER, T.; CARRAHER, D.; SCHLIEMANN, A. Na vida dez, na escola zero. 10. ed. São Paulo: Cortez, 1995. 182 p.

D’AMBROSIO, U. Uma história concisa da matemática no Brasil. 2. ed. Petrópolis: Vozes, 2011. $126 \mathrm{p}$.

EVES, H. Introdução à história da matemática. 1. ed. Campinas: UNICAMP, 2004. 843 p.

FERNANDES, C. T. et al. A construção do conceito de número e o pré-soroban. Brasília: MEC/SEE, 2006.

FEYERABEND, P. Contra o método. 1. ed. Rio de Janeiro: F. Alves, 1977. 488 p. 
FREIRE, P. Pedagogia da autonomia: saberes necessários à prática educativa. 25. ed. São Paulo: Paz e Terra, 2002. $165 \mathrm{p}$.

HESSEN, J. Teoria do conhecimento1. ed. São Paulo: Martins Fontes, 2000. 177 p.

IFRAH, G. Os números: a história de uma grande invenção. 7. ed. São Paulo: Globo, 1994. 367 p.

KAMII, C.; DECLARK, G. Reinventando a aritmética: implicações da teoria de Piaget.13. ed. Campinas: Papirus, 1991. 308 p.

LABURU, C. E.; ARRUDA, S. M.; NARDI, R. Pluralismo metodológico no ensino de ciências. Ciência \& Educação, Bauru, v. 9, n. 2, p. 247-260, 2003.

LERNER, D.; SADOVSKY, P. O sistema de numeração: um problema didático. In: PARRA, C. SAIZ, I. (Org.). Didática da matemática: reflexões psicopedagógicas. Porto Alegre: Ed. Artmed. 1996. p. 73-155.

MARANHÃO, M. C. S. A.; IGLIORI, S. B. C. Registros de representações e números racionais. In: MACHADO, S. D. A. (Org.). Aprendizagem em matemática: registros de representação semiótica. Campinas: Ed. Papirus, 2003. p. 57-70.

MOREIRA, H.; CALEFFE, L. G. Metodologia da pesquisa para o professor pesquisador. 2. ed. Rio de Janeiro: Lamparina, 2008. 245 p.

NOGUEIRA, N. R. Pedagogia dos projetos: uma jornada interdisciplinar rumo ao desenvolvimento das múltiplas inteligências. 1. ed. São Paulo: Érica, 2001. 196 p.

NUNES, T.; BRYANT, P. Crianças fazendo matemática. 1. ed. Porto Alegre: Artmed, 1997. 244 p.

OECD. Programme for International Student Assessment (PISA). Results from PISA 2012: Brazil, 2012. Disponível em <http://www.oecd.org/education/PISA-2012-results-brazil.pdf >. Acesso em 10 dez. 2014.

PAIS, L. C. Didática da matemática: uma análise da influência francesa. 1. ed. Belo Horizonte: Autêntica, 2001. 258 p.

Ensinar e aprender matemática. 2. ed. Belo Horizonte: Autêntica, 2006. 152 p.

PARANÁ. Diretrizes curriculares da educação básica: matemática. Curitiba: SEED, 2008.

PAVANELLO, R. M. (Org.). Matemática nas séries iniciais do ensino fundamental: a pesquisa em sala de aula. 1. ed. São Paulo: Biblioteca do Educador Matemático, 2004. 143 p.

REGNER, A. C. K. P. Feyerabend e o pluralismo metodológico. Caderno Catarinense de Ensino de Física, Florianópolis, v. 13, n. 3, p. 231-247, dez. 1996.

SANTOS, V. M. A matemática escolar, o aluno e o professor: paradoxos aparentes e polarizações em discussão. Cadernos Cedes, Campinas, v. 28, n. 74, p. 25-38, jan./abr. 2008. Disponível em <http://www.scielo.br/pdf/ccedes/v28n74/v28n74a03.pdf>. Acesso em: 09 mar. 2015.

SIMONS, U. M. Blocos lógicos: 150 exercícios para flexibilizar o raciocínio. 1. ed. Petrópolis: Vozes, 2007. $215 \mathrm{p}$. 
SIQUEIRA-BATISTA, R.; SIQUEIRA-BATISTA, R.; SCHRAMM, F. R. A ciência, a verdade e o real: variações sobre o anarquismo epistemológico de Paul Feyerabend. Caderno Brasileiro de Ensino de Física, Florianópolis, v. 22, n. 2, p. 240-262, ago. 2005.

VIANA, C. R. Operações fundamentais: história e ensino - parte I e II. Educação Matemática em Foco, Campina Grande, ano 4, n. 13, maio/ago. 2010.

Submetido em Maio de 2016. Aprovado em Outubro de 2016. 